\title{
Association between sagittal balance and adjacent segment degeneration in anterior cervical surgery: a systematic review and meta-analysis
}

Yijian Zhang ${ }^{1,2 \dagger}$, Yijie Shao ${ }^{1,2 \dagger}$, Hao Liu ${ }^{1,2+}$, Junxin Zhang ${ }^{1,2}$, Fan He ${ }^{1,2}$, Angela Chen ${ }^{3}$, Huilin Yang ${ }^{1,2^{*}}$ and Bin Pi $\mathrm{Pi}^{1,2^{*}}$

\begin{abstract}
Background: ASD is a relatively common degenerative alteration after cervical surgery which occurs above or below the fused segment. In addition, some patients may need reoperation to treat severe ASD after the primary surgery. It was considered that sagittal balance is correlated with postoperative clinical outcomes; however, few studies have reported the influence of sagittal balance on ASD. The present study is designed to investigate whether sagittal balance impacts the pathology of adjacent segment disease (ASD) in patients who undergo anterior cervical surgery for degenerative cervical disease.
\end{abstract}

Methods: Databases including Pubmed, Embase, Cochrane library, and Web of Science were used to search for literature published before June 2018. Review Manager 5.3 was used to perform the statistical analysis. Sagittal balance parameters before and after surgery were compared between patients with and without ASD. Weighted mean difference (WMD) was summarized for continuous data and $P<0.05$ was set for the level of significance.

Results: A total of 221 patients with ASD and 680 patients without ASD from seven articles were studied in this metaanalysis. There were no significant differences in most sagittal balance parameters between the two groups, except for postoperative cervical lordosis (CL) (WMD -3.30, Cl -5.91, - 0.69, $P=0.01$ ).

Conclusions: Some sagittal balance parameters may be associated with the development of ASD after anterior cervical surgery. Sufficient restoration of CL may decrease the incidence of ASD. The results in present study needed to be expanded carefully and further high-quality studies are warranted to investigate the impact of sagittal balance on ASD.

Keywords: Sagittal balance, Adjacent segment degeneration, Cervical degenerative disease, Anterior cervical surgery

\section{Introduction}

Cervical degenerative disease is common among elderly people, and manifests as neck pain, cervical radiolopathy and myelopathy [1]. Clinical symptoms, caused by compression of the nerve root and spinal cord, may include disc protrusion, spondylotic bone spurs, and ligament thickening [2]. The surgical procedure for treating this disease can effectively improve radiographic and clinical outcomes, and has been frequently used in the past few

\footnotetext{
* Correspondence: suzhouspine@163.com; bpi@suda.edu.cn

†Yijian Zhang, Yijie Shao and Hao Liu contributed equally to this work.

${ }^{1}$ Department of Orthopedics, The First Affiliated Hospital of Soochow

University, 899, Pinghai Road, Suzhou 215006, China

Full list of author information is available at the end of the article
}

decades [3]. Compared to other approaches, anterior procedures including anterior cervical discectomy and fusion (ACDF), anterior cervical corpectomy and fusion (ACCF), cervical disc arthroplasty (CDA), and total disc replacement (TDR) can restore cervical lordosis better and achieve preferred exposure and decompression [4, 5]. However, anterior cervical surgery has many drawbacks such as cage subsidence, dysphagia, and elevated rates of pseudoarthrosis [6].

Adjacent segment disease (ASD) refers to recurrent radicular or myelopathic symptoms from adjacent degeneration after surgery [7]. It has been recognized as an important complication after anterior cervical discectomy and fusion, and may be related to many factors [7].

(c) The Author(s). 2019 Open Access This article is distributed under the terms of the Creative Commons Attribution 4.0 International License (http://creativecommons.org/licenses/by/4.0/), which permits unrestricted use, distribution, and reproduction in any medium, provided you give appropriate credit to the original author(s) and the source, provide a link to the Creative Commons license, and indicate if changes were made. The Creative Commons Public Domain Dedication waiver (http://creativecommons.org/publicdomain/zero/1.0/) applies to the data made available in this article, unless otherwise stated. 
A meta-analysis by Wang et al. [8] reported a $6.2 \%$ incidence of ASD after single-level ACDF and found that old age and the development of canal stenosis were risk factors for ASD. Bydon et al. [9] analyzed the location and length of arthrodesis for index ACDFs and found that stress and instability introduced during surgery may result in the pathogenesis of ASD. Unfortunately, the exact etiology of ASD has not yet been illuminated.

Recently, the restoration of sagittal balance after cervical surgery has been emphasized more frequently. Postoperative sagittal balance of the cervical spine is considered to be correlated with clinical outcomes. Kato et al. [10] reported an association between postoperative cervical deformity and outcomes which indicate that poor cervical alignment after surgery may predict a worse SF-36 PCS. Furthermore, previous studies revealed that sagittal balance was related to postoperative ASD. Faldini et al. [11] found that a postoperative segmental alignment greater than $0^{\circ}$ increased the incidence of adjacent-level degeneration. $\mathrm{Hu}$ et al. [12] also reported that patients without improved cervical lordosis had a higher incidence of ASD, worse NDI scores and neck pain. Conversely, some studies reported no impact of sagittal balance on the progression of ASD [13]. Hence, we aim to investigate whether sagittal balance of the cervical spine influences postoperative ASD after anterior cervical surgery by reviewing the previous literature.

\section{Methods}

\section{Search strategy}

This systematic review and meta-analysis followed the according PRISMA statement and guidelines $[14,15]$. The literature research was performed using Pubmed, Embase, Cochrane library, and the Web of Science before June 2018. The search terms combined the following items: "sagittal balance", "sagittal alignment", "sagittal imbalance", "cervical lordosis", "segmental lordosis", "sagittal vertical axis", "T1 slope", "adjacent segment disease", and "adjacent segment degeneration". The reference lists of all articles were reviewed for additional information and the language was restricted to English. The identified articles were evaluated independently by two reviewers (B P and YJ Z) in terms of the inclusion criteria.

\section{Selection criteria}

The eligible studies included in this systematic review and meta-analysis met the following inclusion criteria: (1) randomized controlled trials or comparative studies (retrospective and prospective) of patients undergoing anterior cervical surgery; (2) patients were divided into two groups: those with ASD and those without ASD; (3) measured at least one sagittal balance parameter of the cervical spine; (4) follow-up time more than 1 year. The studies were excluded if: (1) sagittal balance parameters were not measured; (2) patients were not grouped by the presence of ASD; (3) abstracts, case reports, conference presentations, editorials and expert opinions; (4) biomechanical or corpse research. The Newcastle-Ottawa Scale was applied for evaluating of the quality of included studies.

\section{Data extraction}

All potential studies were extracted from full texts, tables, and figures and assessed by two reviewers (B P and YJ Z) independently for inclusion. Discrepancies and doubtful cases were discussed to reach consensuses. The authors, year of publication, type of study, patient characteristics, surgical procedures, follow-up time, and sagittal balance parameters of the cervical spine (cervical lordosis, segmental lordosis, cervical range of motion, segmental range of motion) before and after surgery were all extracted from eligible studies.

\section{Statistical analysis}

The statistical analysis was conducted using Review Manager Version 5.3 (Nordic Cochrane Centre, Cochrane Collaboration, Copenhagen, Sweden). The mean and standard deviation were integrated into the weighted mean difference (WMD) for continuous parameters, and a 95\% confidence interval $(\mathrm{CI})$ was used for statistical analysis. $P$ values less than 0.05 were considered statistically significant. Both fixed- and random- effect models were tested. $x^{2}$ tests and $I^{2}$ statistics were used to study the heterogeneity between trials. The random-effects model was used when heterogeneity was significant $\left(I^{2}>50 \%\right.$ and $P<0.10$ ); otherwise, the fixed-effects model was used.

\section{Results}

\section{Included studies}

A flow diagram outlining the systematic review process is shown in Fig. 1. A total of 991 studies were found (985 searches identified through database and 6 identified through other sources). After elimination of duplicates, 578 records were screened, and 46 full-text articles were assessed for eligibility. Thirty-nine articles were subsequently excluded for having no comparative data, no anterior cervical surgery, or being comment/editorial articles. Ultimately, a total of seven articles were included in this meta-analysis (Table 1). Sagittal balance parameters measured in all studies included preoperative cervical lordosis (CL) $(N=4)$, segmental lordosis (SL) $(N=5)$, cervical range of motion $(N=5)$, segmental range of motion $(N=5)$, postoperative cervical lordosis $(\mathrm{CL})(N=$ $4)$, segmental lordosis (SL) $(N=3)$, cervical range of motion $(N=4)$, and segmental range of motion $(N=4)$. All the included studies attained favorable NewcastleOttawa Scale (scores larger than 7 points), indicating a reliability of these studies (Table 2). 


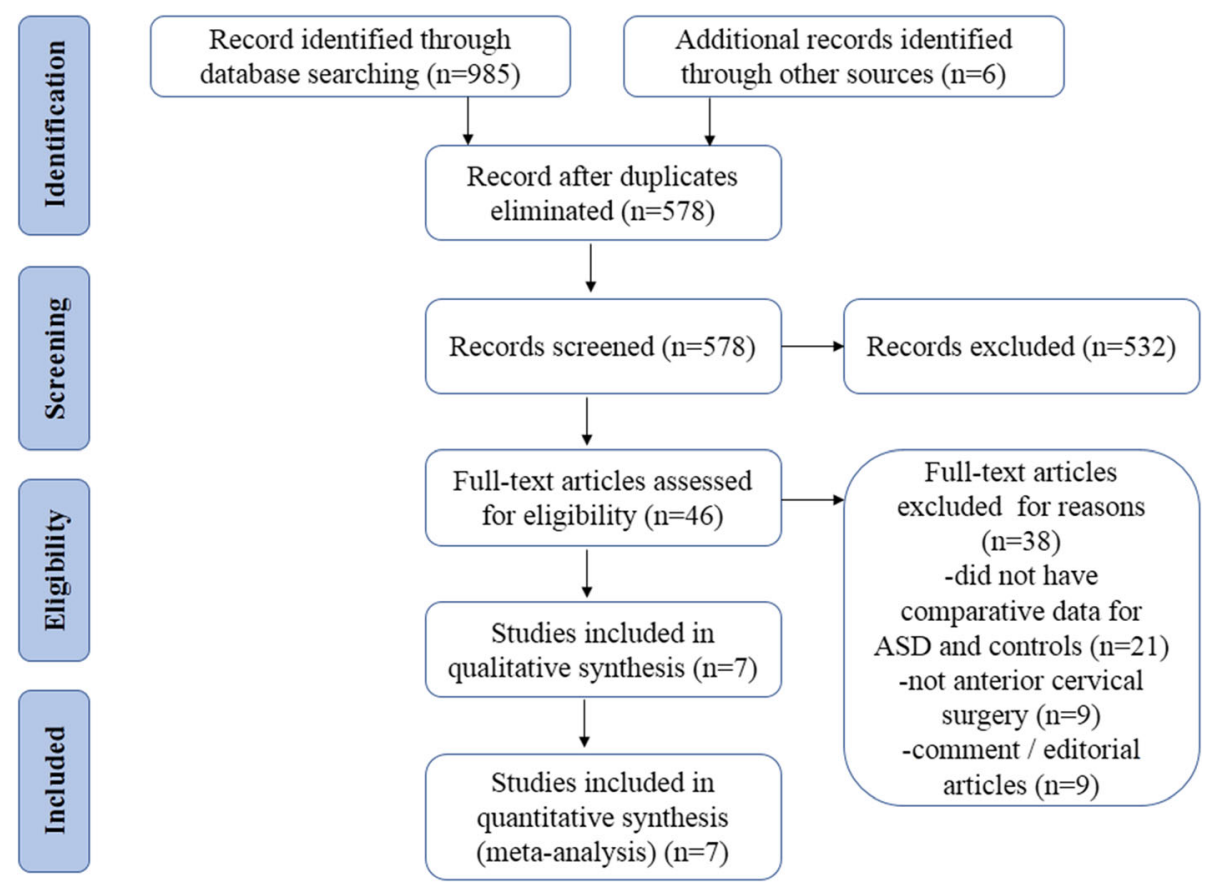

Fig. 1 Flowchart of the selection of literatures

\section{Patients cohort}

ASD was defined as the presence of at least one of the following criteria in radiographic finding: (1) new or enlarging anterior or posterior osteophyte formation; (2) new or developed calcification of the anterior or posterior longitudinal ligament; (3) new occurrence of a disc space narrowing less than $30 \%$ of the intervertebral disc space. A total of 221 patients with ASD and 680 patients without ASD were included in this meta-analysis. The mean age was 48.7 years in the ASD group $(N=4)$ and
50.6 in the non-ASD group $(N=4)$, which created no significant difference $(P=0.36)$. In addition, there was no significant difference in the proportion of males between the ASD $(59 / 99, N=4)$ and non-ASD groups $(250 / 464, N=4)(P=0.40)$.

\section{Sagittal balance parameters}

For the preoperative data, there was no significant difference in CL between patients with and without ASD (WMD -2.19, CI -4.87, 0.48, $P=0.11$ ) associated with

Table 1 Characteristics of included studies

\begin{tabular}{|c|c|c|c|c|c|c|c|c|}
\hline Authors & Year & Study type & Age (years) & Male & $\begin{array}{l}\text { Surgical } \\
\text { procedure }\end{array}$ & Follow-up & $\begin{array}{l}\mathrm{N} \\
(\mathrm{ASD})\end{array}$ & $\begin{array}{l}\mathrm{N} \\
\text { (Controls) }\end{array}$ \\
\hline $\begin{array}{l}\text { Katsuura } \\
\text { et al. [16] }\end{array}$ & 2001 & $\begin{array}{l}\text { Retrospective } \\
\text { study }\end{array}$ & $\begin{array}{l}48.1 \text { for } \mathrm{ASD} \text { and } \\
52.7 \text { for Control }\end{array}$ & $\begin{array}{l}\text { 19/21 for ASD and 15/ } \\
21 \text { for Control }\end{array}$ & ACDF & $\begin{array}{l}122.4 \text { months for ASD and } 112.7 \\
\text { months for Control }\end{array}$ & 21 & 21 \\
\hline $\begin{array}{l}\text { Kim et al. } \\
{[17]}\end{array}$ & 2015 & $\begin{array}{l}\text { Prospective } \\
\text { study }\end{array}$ & 43.52 & $117 / 180$ & TDR & Mean 48.6 months & 73 & 107 \\
\hline \multirow[t]{2}{*}{$\begin{array}{l}\text { Lee et al. } \\
\text { [18] }\end{array}$} & 2015 & $\begin{array}{l}\text { Retrospective } \\
\text { study }\end{array}$ & 47.1 & $12 / 14$ & CDA & Mean 43.4 months & 5 & 9 \\
\hline & & $\begin{array}{l}\text { Retrospective } \\
\text { study }\end{array}$ & 53.6 & $24 / 28$ & ACDF & Mean 44.6 months & 16 & 12 \\
\hline $\begin{array}{l}\text { Li et al. } \\
\text { [19] }\end{array}$ & 2015 & $\begin{array}{l}\text { Retrospective } \\
\text { study }\end{array}$ & 50.2 & $61 / 106$ & ACDF & $\begin{array}{l}30.6 \text { months for ASD and } 31.2 \\
\text { months for non-ASD }\end{array}$ & 28 & 88 \\
\hline $\begin{array}{l}\text { Song et al. } \\
{[20]}\end{array}$ & 2018 & $\begin{array}{l}\text { Retrospective } \\
\text { study }\end{array}$ & $\begin{array}{l}51.8 \text { for } \mathrm{ASD} \text { and } \\
48.5 \text { for } \mathrm{N}-\mathrm{ASD}\end{array}$ & $\begin{array}{l}11 / 25 \text { for } A S D \text { and } 85 / \\
175 \text { for } N-A S D\end{array}$ & $\begin{array}{l}\text { ACCF and } \\
\text { ACDF }\end{array}$ & $\begin{array}{l}34.2 \text { months for ASD and } 34.8 \\
\text { months for N-ASD }\end{array}$ & 25 & 175 \\
\hline $\begin{array}{l}\text { Song et al. } \\
{[21]}\end{array}$ & 2014 & $\begin{array}{l}\text { Retrospective } \\
\text { study }\end{array}$ & $\begin{array}{l}57.73 \text { for ASD and } \\
54.09 \text { for Control }\end{array}$ & $\begin{array}{l}12 / 15 \text { for ASD and } \\
125 / 216 \text { for Control }\end{array}$ & ACDF & Mean 63.85 months & 15 & 216 \\
\hline $\begin{array}{l}\text { Yang et al. } \\
{[22]}\end{array}$ & 2017 & $\begin{array}{l}\text { Retrospective } \\
\text { study }\end{array}$ & $\begin{array}{l}43.3 \text { for } \mathrm{ASD} \text { and } \\
42.6 \text { for } \mathrm{N}-\mathrm{ASD}\end{array}$ & $\begin{array}{l}17 / 21 \text { for ASD and } 25 / \\
27 \text { for N-ASD }\end{array}$ & CDA & $\begin{array}{l}\text { Mean } 79.3 \text { months for SASD and } \\
78.6 \text { months Non-SASD }\end{array}$ & 38 & 52 \\
\hline
\end{tabular}

Abbreviation: $A S D$ adjacent segment disease, $A C D F$ anterior cervical discectomy and fusion, $C D A$ cervical disc arthroplasty 
Table 2 Quality assessment of the enrolled studies

\begin{tabular}{llll}
\hline Authors & Selection & Comparability & Exposure \\
\hline Katsuura2001 et al [35] & $\star \star \star \star$ & $\star \star$ & $\star \star \star$ \\
Kim2015 et al [36] & $\star \star \star \star$ & $\star \star$ & $\star \star \star$ \\
Lee2015 et al [37] & $\star \star \star \star$ & $\star \star$ & $\star \star \star$ \\
Li2014 et al [38] & $\star \star \star \star$ & $\star \star$ & $\star \star$ \\
Song2014 et al [39] & $\star \star \star$ & $\star \star$ & $\star \star \star$ \\
Song2018 et al [40] & $\star \star \star \star$ & $\star \star$ & $\star \star$ \\
Yang2017 et al [41] & $\star \star \star$ & $\star \star$ & $\star \star \star$ \\
\hline
\end{tabular}

moderate heterogeneity $\left(I^{2}=52 \%\right)$. Similarly, no significant difference was detected in SL (WMD -0.69, CI $-1.61,0.22, P=0.14$ ), cervical range of motion (WMD -0.25 , CI $-7.66,7.16, P=0.95)$, and segmental range of motion (WMD 0.10, CI $-0.60,0.79, P=0.79$ ) with different heterogeneity $\left(I^{2}=0 \%, I^{2}=77 \%, I^{2}=34 \%\right.$, respectively) (Figs. 2 and 3).

For the postoperative data, there was no significant difference in SL (WMD -0.69, CI -3.06, 1.67, $P=0.57$ ), cervical range of motion (WMD 0.60, CI -4.32, 5.51, $P=$ 0.81 ), and segmental range of motion (WMD -1.58, CI -3.37, 0.20, $P=0.08$ ) between the two groups with distinctive heterogeneity $\left(I^{2}=77 \%, I^{2}=0 \%, I^{2}=78 \%\right.$, respectively). It is noted that a significant difference was shown in CL between patients with and without ASD (WMD -3.30, CI -5.91, $-0.69, P=0.01$ ) associated with moderate heterogeneity $\left(I^{2}=63 \%\right)$ (Figs. 4 and 5 ).

\section{Clinical assessment}

For the preoperative data, there was no significant difference in JOA and NDI between patients with and without
ASD (WMD 0.06, CI -1.23, 1.36, $P=0.92$ ) (WMD 0.74, CI $-1.18,2.66, P=0.45)$ associated with moderate and low heterogeneity, respectively (I2 $=65 \%, \mathrm{I} 2=0 \%)$. Similarly, no significant difference was detected in VAS-neck (WMD 0.06, CI -0.68,0.80, $P=0.87$ ) and VAS-arm (WMD 0.12 , CI $-0.50,0.74, P=0.70$ ) with low heterogeneity ( $\mathrm{I} 2=0 \%, \mathrm{I} 2=21 \%$ ) (Figs. 6 and 7 ).

For the postoperative data, there was no significant difference in JOA (WMD -0.50, CI -1.26, 0.27, $P=0.20$ ) and VAS-arm (WMD 0.23, CI -0.16, 0.62, $P=0.24$ ) between the two groups with low heterogeneity (I2 $=0 \%$, $\mathrm{I} 2=0 \%)$. It is noted that a significant difference was shown in NDI and VAS-neck between patients with and without ASD (WMD 1.06, CI 0.03, 2.09, P=0.04) (WMD 0.56, CI $0.14,0.98, P=0.01$ ) associated with low heterogeneity (I2 $=0 \%, \mathrm{I} 2=0 \%)$ (Figs. 8 and 9) (Additional file 1).

\section{Discussion}

Anterior cervical surgery including anterior cervical discectomy and fusion (ACDF), anterior cervical corpectomy and fusion (ACCF), and cervical disc arthroplasty (CDA) have all proved to be effective procedures for the treatment of cervical degenerative disease. Operative treatment can dramatically bring the imbalanced sagittal curve closer to a normal lordotic alignment and increase disc height, relieving neck pain and improving quality of life [23, 24]. However, various complications such as dysphagia, C5 nerve palsy, implant failure, and adjacent segment disease may also occur after surgery [25].

Adjacent segment disease (ASD) is a common complication after cervical surgery and is defined as the development of new clinical symptoms that correspond to the

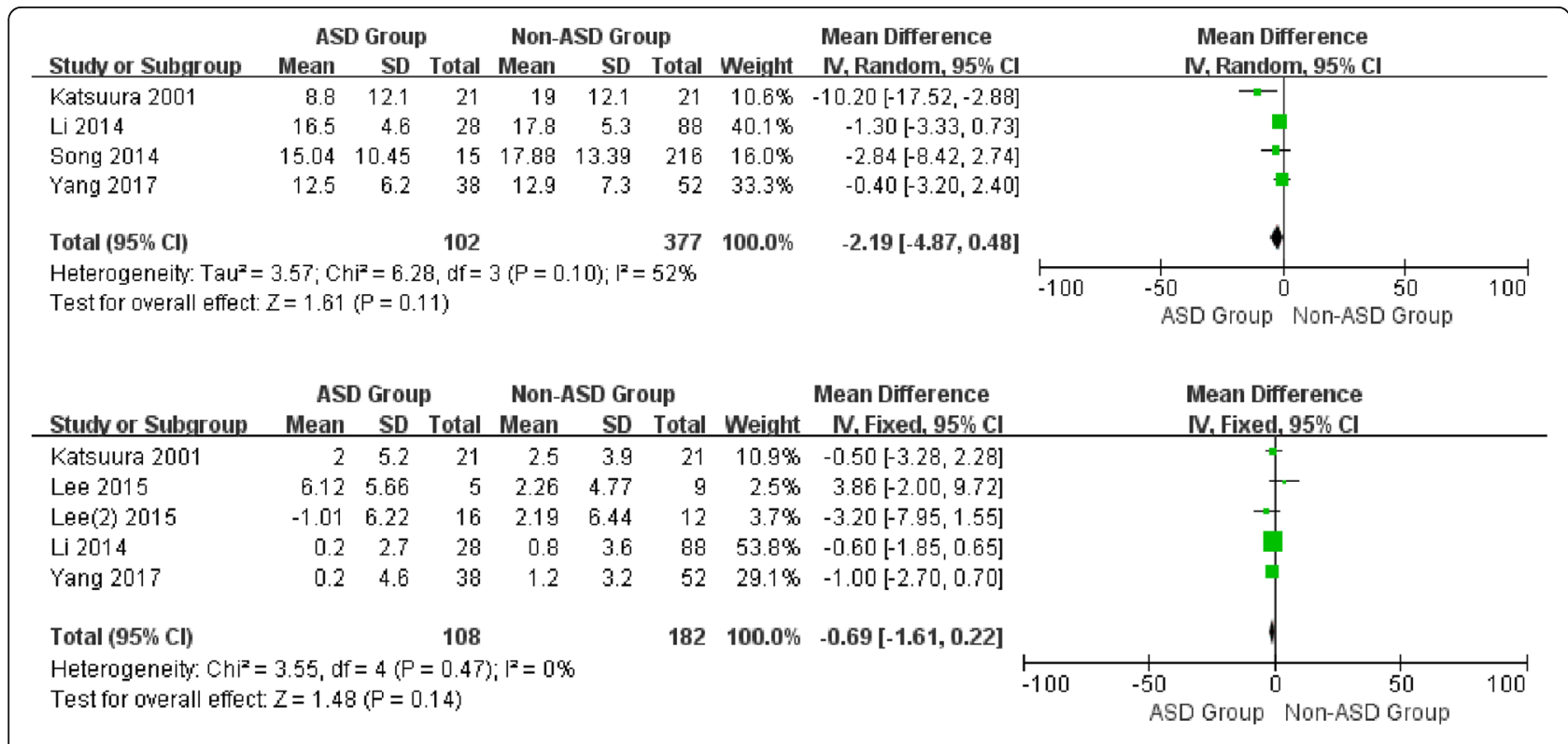

Fig. 2 Forest plot of ASD group and non-ASD group: Comparison of preoperative cervical lordosis (above) and preoperative segmental lordosis (below) 


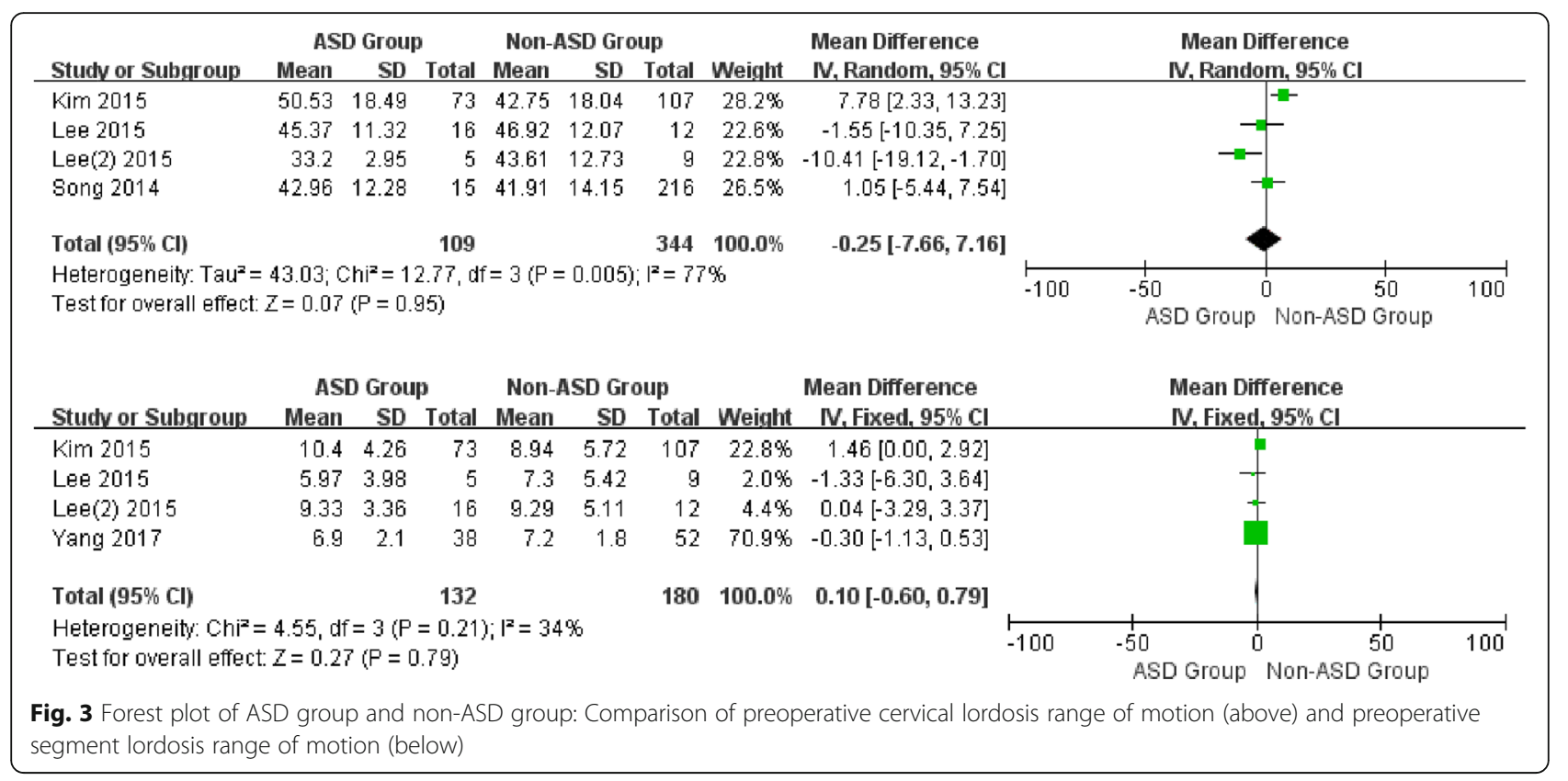

radiographic change to the level of the previous spinal fusion [26]. Patients with postoperative ASD may have uncomfortable symptoms including neck pain, stiffness and activity limitation. In this study, we revealed compared with non-ASD, patients with ASD had prominently worse NDI and VAS-neck scores. The symptomatic ASD after ACDF was reported to be at a relatively constant incidence of $2.9 \%$ per year [27], however, our metaanalysis revealed that the integrated incidence of ASD was
$24.5 \%$ (221/901) from the seven articles included, all of which had at least 2 years follow-up. We concluded that this may be attributed to the definition of ASD, which requires both radiographic and symptomatic ASD. Generally, radiographic alteration of ASD can be detected via MRI after cervical surgery, but only a fraction may develop into symptomatic ASD that requires reoperation. Wu et al. [28] analyzed an 11-year national database in Taiwan and found that while the incidence of the repeated ACDF

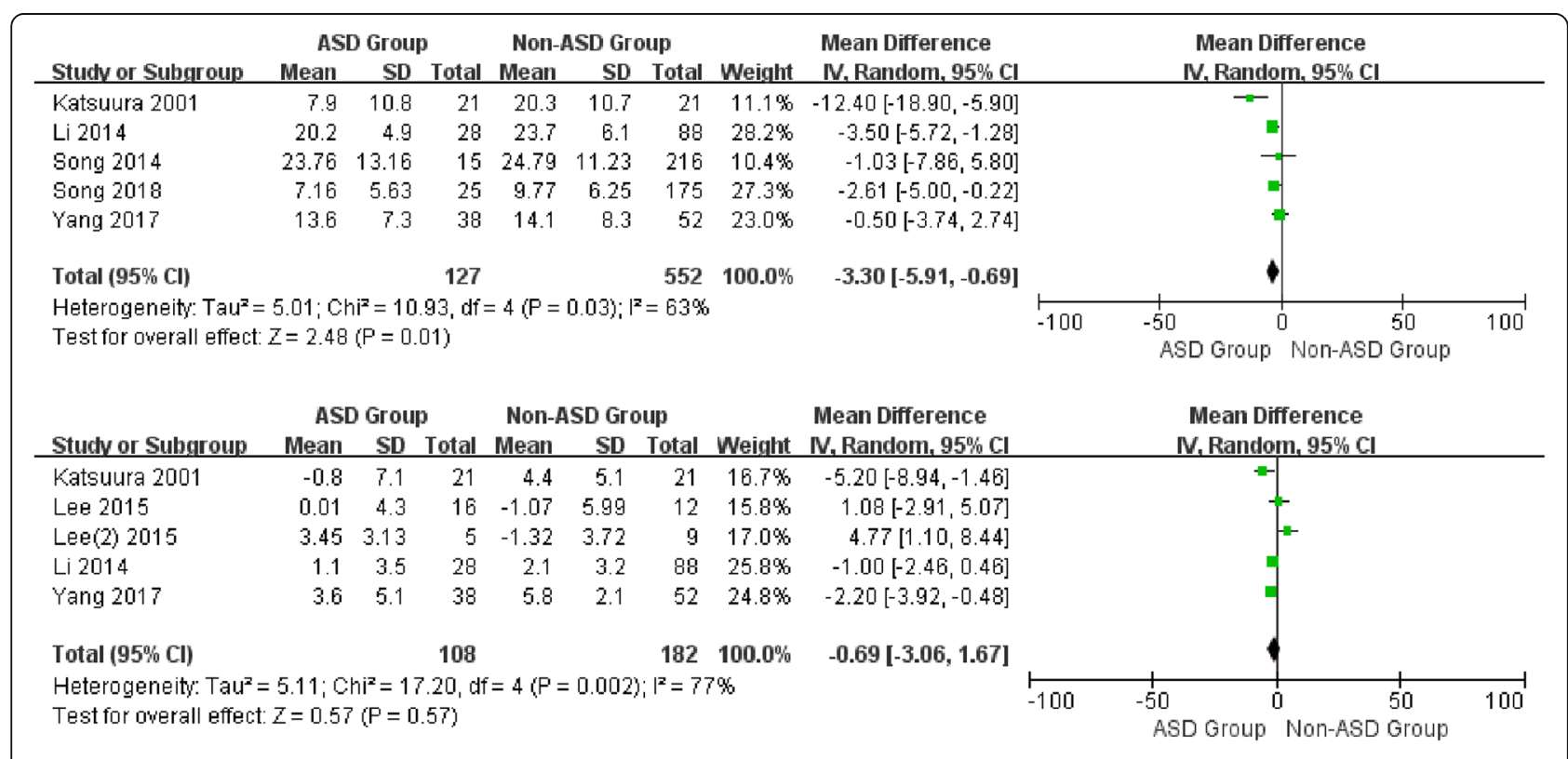

Fig. 4 Forest plot of ASD group and non-ASD group: Comparison of postoperative cervical lordosis (above) and postoperative segmental lordosis (below) 


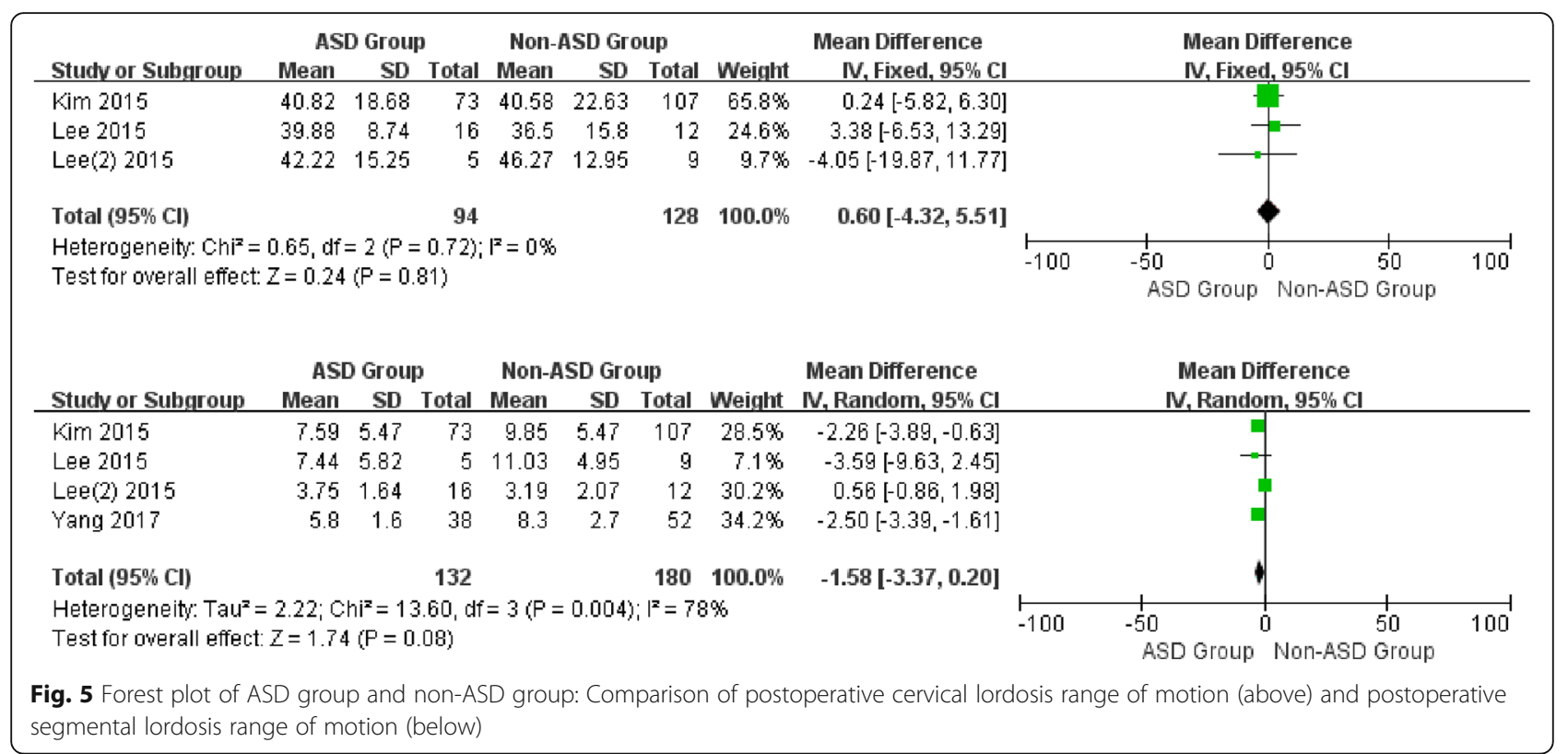

for ASD was approximately $0.8 \%$, as much as $5.6 \%$ patients received a second operation at the end of the 10year cohort. This indicated that the risk of reoperation for ASD may increase over time.

The pathology of ASD is a complicated process and may be attributed to multiple factors. Nunley et al. [29] reported that osteopenia $(\mathrm{OD}=9.35)$ and documented lumbar degenerative disc disorder $(\mathrm{OD}=5.13)$ were two independent risk factors for ASD in patients undergoing total disc replacement. Yu et al. [30] found that older age, poor restoration of postoperative cervical lordosis, and a plate to disc distance less than $5 \mathrm{~mm}$ may result in ASD after cervical fusion. Lee et al. [31] revealed that patients with one- or two- level anterior arthrodesis and those who smoked were more likely to receive an adjacent segment surgery within 10 years. Recently, some studies indicated that postoperative restoration of sagittal balance may be related to clinical outcomes [32]. Furthermore, it was reported that sagittal balance of the cervical spine may be associated with ASD. Alhashash

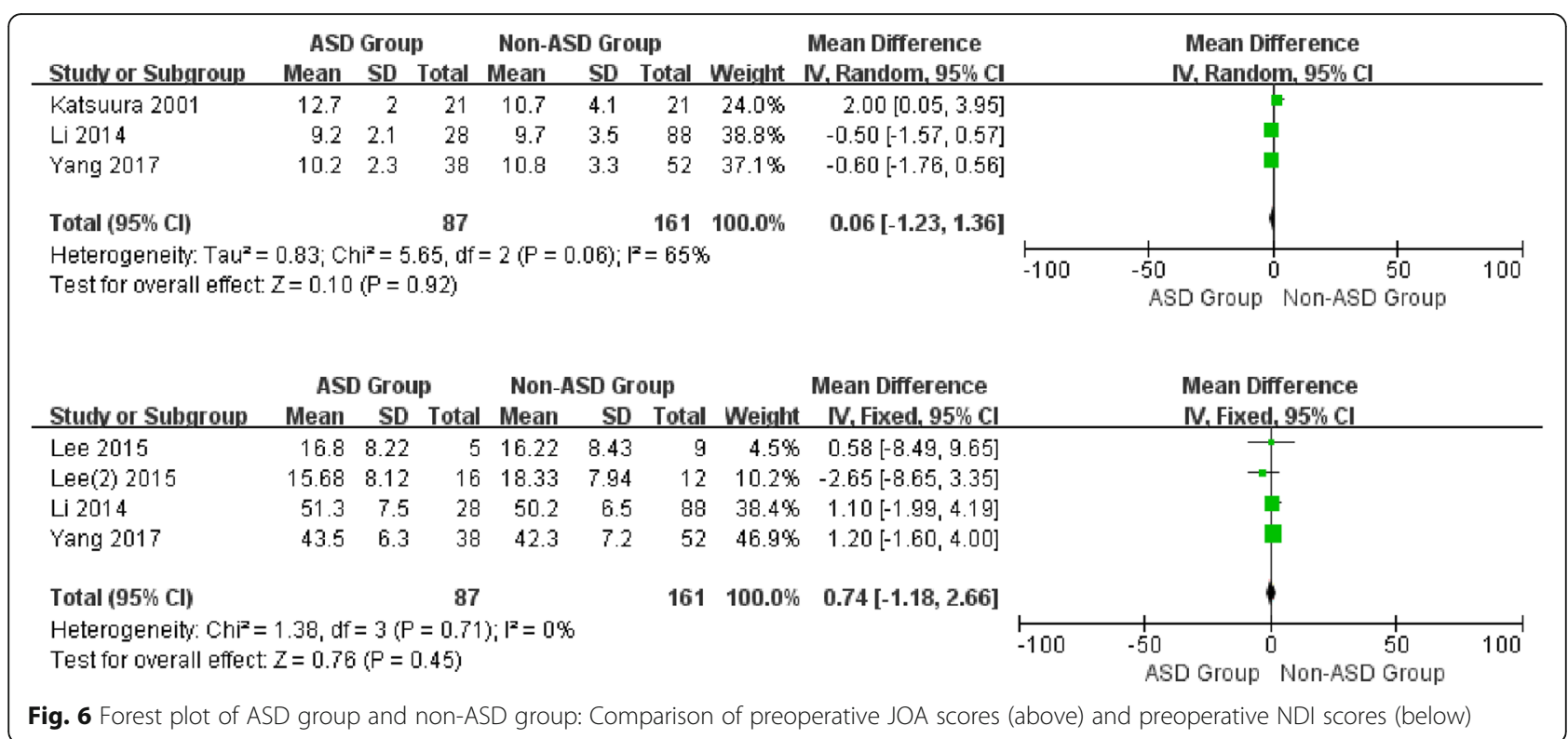




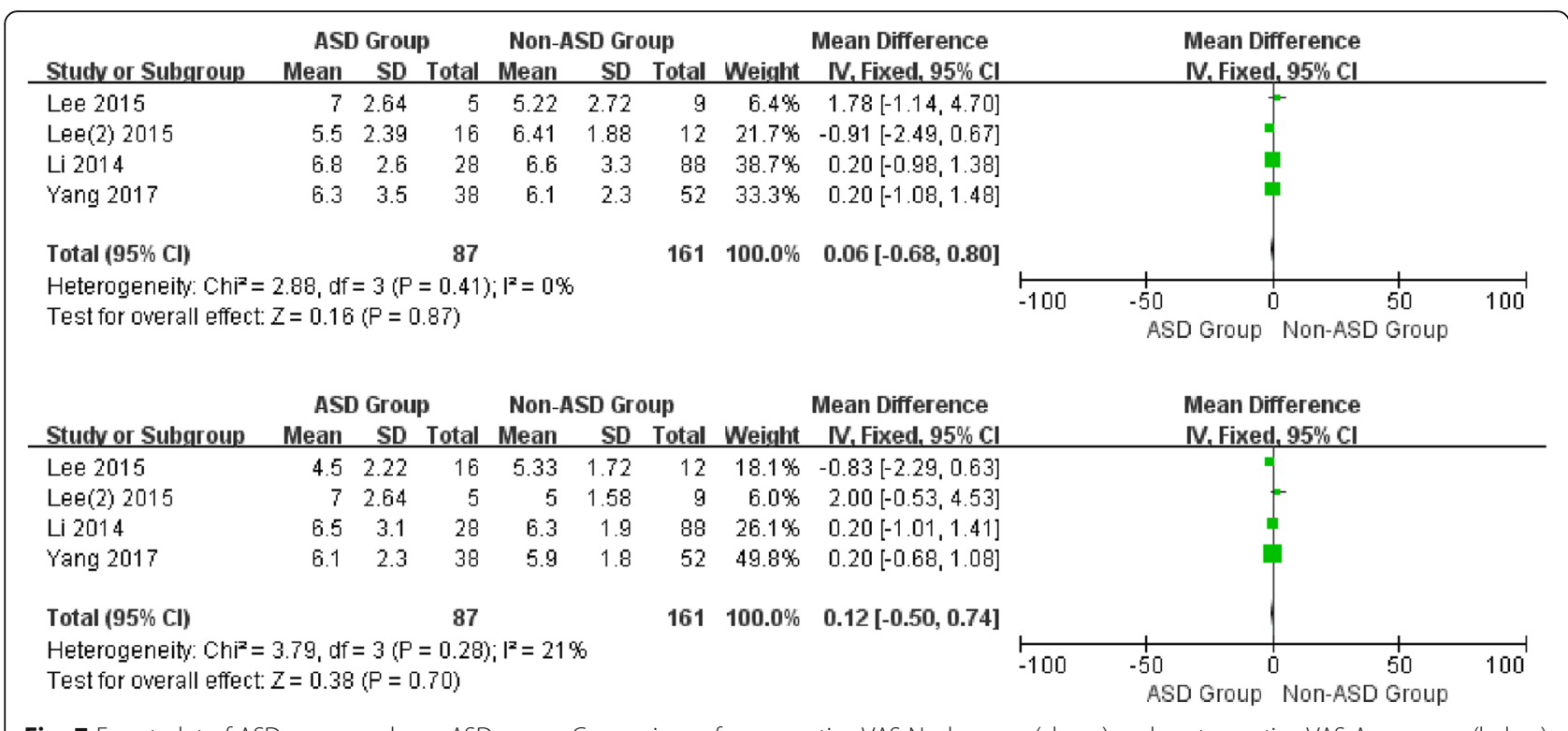

Fig. 7 Forest plot of ASD group and non-ASD group: Comparison of preoperative VAS-Neck scores (above) and postoperative VAS-Arm scores (below)

et al. [33] demonstrated that ASD is more likely to occur in single level fusion and that restoration and preservation of cervical sagittal alignment can significantly reduce the risk of ASD. Another study also verified that malalignment of the cervical spine following anterior cervical fusion can lead to the development of ASD [34]. Conversely, Park et al. [35] found that several radiographic parameters were unrelated to postoperative ASD, indicating that ASD is associated with a natural degenerative process instead of operative complications. In our meta-analysis, most sagittal balance parameters showed no significant difference between ASD and nonASD patients. It is worth noting that a significant difference was detected in postoperative CL between two groups $(\mathrm{OR}=-3.32, P=0.02)$, which indicates that $\mathrm{CL}$ restoration may be correlated with the development of postoperative ASD.

The natural curvature of the cervical spine maintains a lordotic shape to maintain the wedge-shaped cervical vertebrae and compensate for the kyphotic curvature of the thoracic spine [36]. Nevertheless, increasing age and long-term improper posture may alter the normal alignment of the cervical spine, and even result in progressive cervical kyphosis. Furthermore, the deformity can lead to draping of the spinal cord against the vertebral bodies and increase longitudinal cord tension, which subsequently

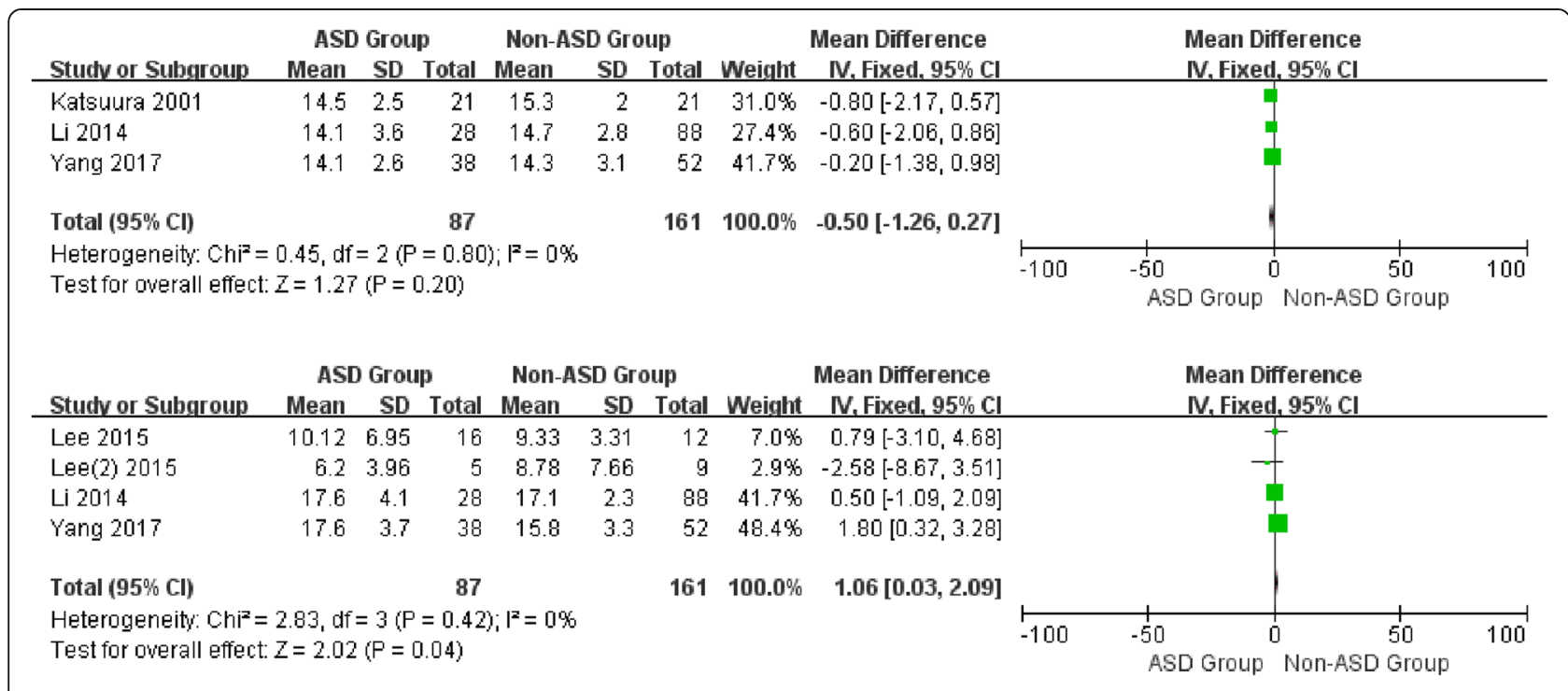

Fig. 8 Forest plot of ASD group and non-ASD group: Comparison of postoperative JOA scores (above) and postoperative NDI scores (below) 


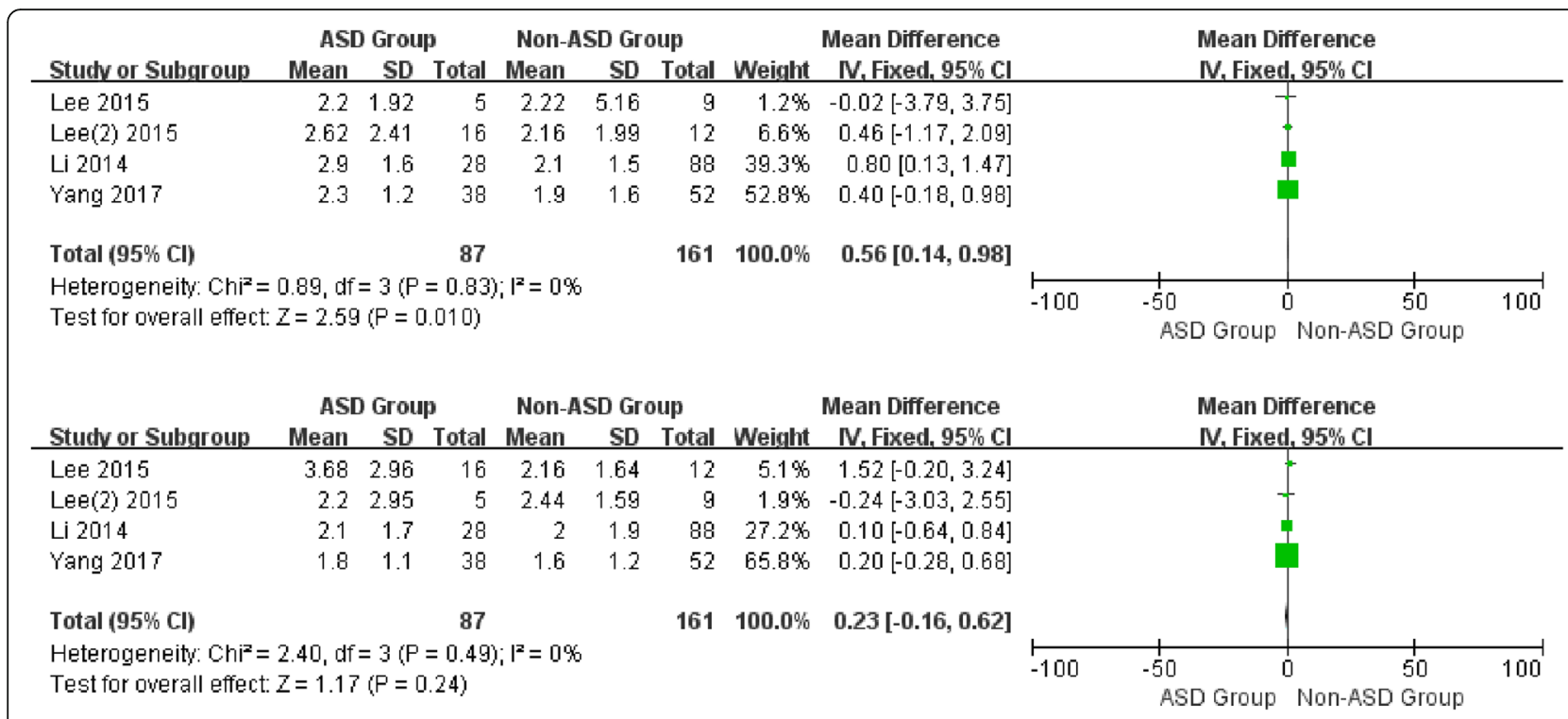

Fig. 9 Forest plot of ASD group and non-ASD group: Comparison of postoperative VAS-Neck scores (above) and postoperative VAS-Arm scores (below)

compresses the spinal cord and nerve root [37]. Although symptoms can be alleviated via the surgical procedures including ACCF and CDA, simple decompression without the correction of deformity, especially cervical kyphosis, may not result in satisfied outcomes. It was considered that insufficient correction of sagittal balance may contribute to the pathology of ASD due to increased anterior loads and pressure [38]. Biomechanical results showed that intradiscal stress and ROM at the adjacent segment changed more in the postoperative model with less lordosis, which illustrated that decreased lordosis may result in alteration of the adjacent segment and subsequently lead to the onset of ASD [39]. Despite several sagittal balance parameters in this meta-analysis, our results showed no significant difference between ASD and non-ASD patients, and the crucial parameter "postoperative CL" differed significantly. It has been suggested that CL is the optimal parameter to depict cervical alignment and that it correlates with several other sagittal balance parameters like $\mathrm{T} 1$ slope and SVA [40]. Indeed, C2 7 SVA is regarded as an important sagittal balance parameters, however, because of the limited data the authors cannot analyze the impact of C2 7 SVA on ASD. On the other hand, CL proved to be more important in relation to long-term clinical outcomes [41]. Hence, we speculate that the progression of ASD may result from the abnormal stress distribution of adjacent segments and the increased tension in the posterior column when moving the segments, caused by decreased CL after surgery.

\section{Limitations}

There are some limitations in this meta-analysis - first, only seven articles were enrolled. This is because few studies have focused on the relationship between sagittal balance and ASD and grouped patients by ASD and non-ASD. Second, this study consisted of one prospective cohort study and six retrospective studies, which may lead to less powerful results compared with randomized controlled trials. Third, due the limited enrolled studies, the heterogeneity in some results were substantial, which may lead to unpowered evidence. Forth, though C2 7 SVA was an important sagittal balance parameters, insufficient data from published articles cannot be analyzed in this study. Fifth, the original data, especially the complete sagittal balance parameters from the included articles, failed to be obtained in this study, which may limit the credibility and reliability of our results. Lastly, since ASD measurement is unstandardized across the different countries included, this may cause some discrepancies between the results. Therefore, more randomized controlled trials of high quality that focus on more detailed sagittal balance parameters are needed to analyze the association between sagittal balance and ASD.

\section{Conclusion}

The sagittal balance parameter postoperative $\mathrm{CL}$ is a crucial factor which may predict the development of ASD. Sufficient restoration of CL may decrease the incidence of ASD in patients undergoing anterior cervical surgery for degenerative cervical disease. Due to the limited studies and moderate heterogeneity, the conclusions of the present study need to be interpreted with caution. More studies with strong evidence and adequate parameter were needed to verify our conclusion in future. 


\section{Additional file}

Additional file 1: Publication bias and sensitivity analysis. (TIF 7608 kb)

\section{Abbreviations}

ACCF: Anterior cervical corpectomy and fusion; ACDF: Anterior cervical discectomy and fusion,; ASD: Adjacent segment disease; CDA: Cervical disc arthroplasty; TDR: Total disc replacement; WMD: Weighted mean difference

\section{Acknowledgements}

None.

\section{Authors' contributions}

BP conceived of the study and participated in its design and coordination. $\mathrm{YZ}$ and $\mathrm{HL}$ drafted the manuscript. $\mathrm{HY}, \mathrm{FH}$, and $\mathrm{AC}$ participated in the design of the study and proposed valuable suggestion. All authors have read and approved the manuscript.

\section{Funding}

The project was supported by the Jiangsu Provincial Clinical Orthopedics Center. Observers and authors were funded in the design of the study, collection and analysis of data, the writing of manuscript, and polishing of English manuscripts with mother tongue.

\section{Availability of data and materials}

The datasets used and / or analyzed during the current study are available from the corresponding author on reasonable request.

\section{Ethics approval and consent to participate}

Not Applicable.

\section{Consent for publication}

Not Applicable.

\section{Competing interests}

The authors declare that they have no competing interest.

\section{Author details}

'Department of Orthopedics, The First Affiliated Hospital of Soochow University, 899, Pinghai Road, Suzhou 215006, China. ${ }^{2}$ Orthopedic Institute, Soochow University, Suzhou 215006, China. ${ }^{3}$ Department of School of Public Health and Health Systems, Faculty of Applied Health Sciences Biochemistry Department, University of Waterloo, Waterloo, Canada.

\section{Received: 19 December 2018 Accepted: 29 August 2019}

\section{Published online: 14 September 2019}

\section{References}

1. Alvin MD, Qureshi S, Klineberg E, Riew KD, Fischer DJ, Norvell DC, Mroz TE. Cervical degenerative disease: systematic review of economic analyses. Spine. 2014;39(22 Suppl 1):S53-64.

2. Kristiansen JA, Balteskard L, Slettebo H, Nygaard OP, Lied B, Kolstad F, Solberg TK. The use of surgery for cervical degenerative disease in Norway in the period 2008-2014: a population-based study of 6511 procedures. Acta Neurochir. 2016;158(5):969-74

3. Matz PG, Anderson PA, Kaiser MG, Holly LT, Groff MW, Heary RF, Mummaneni PV, Ryken TC, Choudhri TF, Vresilovic EJ, et al. Introduction and methodology: guidelines for the surgical management of cervical degenerative disease. J Neurosurg Spine. 2009;11(2):101-3.

4. Asher AL, Devin CJ, Kerezoudis P, Chotai S, Nian H, Harrell FE Jr, Sivaganesan A, McGirt MJ, Archer KR, Foley KT, et al. Comparison of outcomes following anterior vs posterior fusion surgery for patients with degenerative cervical myelopathy: an analysis from quality outcomes database. Neurosurgery. 2018;84:919-26.

5. Witiw CD, Smieliauskas F, OToole JE, Fehlings MG, Fessler RG. Comparison of Anterior Cervical Discectomy and Fusion to Posterior Cervical Foraminotomy for Cervical Radiculopathy: Utilization, Costs and Adverse Events 2003 to 2014. Neurosurgery. 2018;84:413-20.

6. He S, Feng H, Lan Z, Lai J, Sun Z, Wang Y, Wang J, Ren Z, Huang F, Xu F. A randomized trial comparing clinical outcomes between zero-profile and traditional multilevel anterior cervical discectomy and fusion surgery for cervical myelopathy. Spine. 2018;43(5):E259-e266.

7. Schroeder GD, Boody BS, Kepler CK, Kurd MF, Silva S, Nicholson K, Wilson JR, Woods BI, Radcliff KE, Anderson DG, et al. Comparing health-related quality of life outcomes in patients undergoing either primary or revision anterior cervical discectomy and fusion. Spine. 2018;43(13):E752-e757.

8. Wang F, Hou HT, Wang P, Zhang JT, Shen Y. Symptomatic adjacent segment disease after single-lever anterior cervical discectomy and fusion: incidence and risk factors. Medicine. 2017;96(47):e8663.

9. Bydon M, Xu R, Macki M, De la Garza-Ramos R, Sciubba DM, Wolinsky JP, Witham TF, Gokaslan ZL, Bydon A. Adjacent segment disease after anterior cervical discectomy and fusion in a large series. Neurosurgery. 2014;74(2): 139-46 discussion 146

10. Kato S, Nouri A, Wu D, Nori S, Tetreault L, Fehlings MG. Impact of Cervical Spine Deformity on Pre-operative Disease Severity and Post-operative Outcomes Following Fusion Surgery for Degenerative Cervical Myelopathy - Sub-Analysis of AOSpine North America and International Studies. In: Spine; 2017.

11. Faldini C, Pagkrati S, Leonetti D, Miscione MT, Giannini S. Sagittal segmental alignment as predictor of adjacent-level degeneration after a Cloward procedure. Clin Orthop Relat Res. 2011;469(3):674-81.

12. Hu X, Ohnmeiss DD, Zigler JE, Guyer RD, Lieberman IH. Restoration of cervical alignment is associated with improved clinical outcome after one and two level anterior cervical discectomy and fusion. Int J Spine Surg. 2015;9:61

13. Rao RD, Gore DR, Tang SJ, Rebholz BJ, Yoganandan N, Wang M. Radiographic changes in the cervical spine following anterior arthrodesis: a long-term analysis of 166 patients. J Bone Joint Surg Am. 2016;98(19):1606-13.

14. Moher D, Liberati A, Tetzlaff J, Altman DG, Group P. Preferred reporting items for systematic reviews and meta-analyses: the PRISMA statement. PLoS Med. 2009;6(7):e1000097.

15. Phan K, Mobbs RJ. Systematic reviews and meta-analyses in spine surgery, neurosurgery and orthopedics: guidelines for the surgeon scientist. J Spine Surg. 2015;1(1):19-27.

16. Katsuura A, Hukuda S, Saruhashi Y, Mori K. Kyphotic malalignment after anterior cervical fusion is one of the factors promoting the degenerative process in adjacent intervertebral levels. Eur Spine J. 2001;10(4):320-4.

17. Kim SW, Paik SH, Oh JK, Kwak YH, Lee HW, You KH. The impact of coronal alignment of device on radiographic degeneration in the case of total disc replacement. Spine J. 2016;16(4):470-9.

18. Lee SE, Jahng TA, Kim HJ. Correlation between cervical lordosis and adjacent segment pathology after anterior cervical spinal surgery. Eur Spine J. 2015;24(12):2899-909.

19. Li J, Li Y, Kong F, Zhang D, Zhang Y, Shen Y. Adjacent segment degeneration after single-level anterior cervical decompression and fusion: disc space distraction and its impact on clinical outcomes. J Clin Neurosci. 2015:22(3):566-9.

20. Song J, Zhang $Y X$, Song $K H$, Wang HL, Zou F, Jiang JY. Risk Factors of Adjacent Segment Disease After Anterior Cervical Arthrodesis: A Retrospective Study of Sagittal Measurement of Thoracic Inlet Parameters. World Neurosurg. 2018;114:e1094-100.

21. Song KJ, Choi BW, Kim JK. Adjacent segment pathology following anterior decompression and fusion using cage and plate for the treatment of degenerative cervical spinal diseases. Asian Spine J. 2014:8(6):720-8.

22. Yang P, Li Y, Li J, Shen Y. Impact of T1 slope on surgical and adjacent segment degeneration after Bryan cervical disc arthroplasty. Ther Clin Risk Manag. 2017;13:1119-25

23. Godlewski B, Stachura MK, Czepko RA, Banach M, Czepko R. Analysis of changes in cervical spinal curvature and intervertebral disk space height following ACDF surgery in a group of 100 patients followed up for 12 months. J Clin Neurosci. 2018;52:92-9.

24. Muzevic D, Splavski B, Boop FA, Arnautovic Kl. Anterior cervical discectomy with instrumented allograft fusion: lordosis restoration and comparison of functional outcomes among patients of different age groups. World Neurosurg. 2018;109:e233-43.

25. Tasiou A, Giannis T, Brotis AG, Siasios I, Georgiadis I, Gatos H, Tsianaka E, Vagkopoulos K, Paterakis K, Fountas KN. Anterior cervical spine surgeryassociated complications in a retrospective case-control study. J Spine Surg. 2017:3(3):444-59.

26. Hilibrand AS, Robbins M. Adjacent segment degeneration and adjacent segment disease: the consequences of spinal fusion? Spine J. 2004;4(6 Suppl):190s-4s. 
27. Hilibrand AS, Carlson GD, Palumbo MA, Jones PK, Bohlman HH. Radiculopathy and myelopathy at segments adjacent to the site of a previous anterior cervical arthrodesis. J Bone Joint Surg Am. 1999;81(4):519-28.

28. Wu JC, Liu L, Wen-Cheng H, Chen YC, Ko CC, Wu CL, Chen TJ, Cheng H, Su TP. The incidence of adjacent segment disease requiring surgery after anterior cervical diskectomy and fusion: estimation using an 11-year comprehensive nationwide database in Taiwan. Neurosurgery. 2012;70(3): 594-601.

29. Nunley PD, Jawahar A, Cavanaugh DA, Gordon CR, Kerr EJ 3rd, Utter PA. Symptomatic adjacent segment disease after cervical total disc replacement: re-examining the clinical and radiological evidence with established criteria. Spine J. 2013;13(1):5-12.

30. Yu C, Mu X, Wei J, Chu Y, Liang B. In-depth analysis on influencing factors of adjacent segment degeneration after cervical fusion. Med Sci Monit. 2016:22:4902-10.

31. Lee JC, Lee SH, Peters C, Riew KD. Adjacent segment pathology requiring reoperation after anterior cervical arthrodesis: the influence of smoking, sex, and number of operated levels. Spine. 2015;40(10):E571-7.

32. Villavicencio AT, Babuska JM, Ashton A, Busch E, Roeca C, Nelson EL, Mason A, Burneikiene S. Prospective, randomized, double-blind clinical study evaluating the correlation of clinical outcomes and cervical sagittal alignment. Neurosurgery. 2011;68:1309-16 discussion 1316.

33. Alhashash M, Shousha M, Boehm H. Adjacent segment disease after cervical spine fusion: evaluation of a 70 patient long-term follow-up. Spine. 2018; 43(9):605-9.

34. Park MS, Kelly MP, Lee DH, Min WK, Rahman RK, Riew KD. Sagittal alignment as a predictor of clinical adjacent segment pathology requiring surgery after anterior cervical arthrodesis. Spine J. 2014;14(7):1228-34.

35. Park JY, Kim KH, Kuh SU, Chin DK, Kim KS, Cho YE. What are the associative factors of adjacent segment degeneration after anterior cervical spine surgery? Comparative study between anterior cervical fusion and arthroplasty with 5year follow-up MRI and CT. Eur Spine J. 2013;22(5):1078-89.

36. Gay RE. The curve of the cervical spine: variations and significance. J Manip Physiol Ther. 1993;16(9):591-4.

37. Deutsch H, Haid RW, Rodts GE, Mummaneni PV. Postlaminectomy cervical deformity. Neurosurg Focus. 2003;15(3):E5.

38. Scheer JK, Tang JA, Smith JS, Acosta FL Jr, Protopsaltis TS, Blondel B, Bess S, Shaffrey Cl, Deviren V, Lafage V, et al. Cervical spine alignment, sagittal deformity, and clinical implications: a review. J Neurosurg Spine. 2013;19(2): $141-59$.

39. Liu Y, Li N, Wei W, Deng J, Hu Y, Ye B, Wang W. Prognostic value of lordosis decrease in radiographic adjacent segment pathology after anterior cervical Corpectomy and fusion. Sci Rep. 2017;7(1):14414.

40. Zhang JT, Li JQ, Niu RJ, Liu Z, Tong T, Shen Y. Predictors of cervical lordosis loss after laminoplasty in patients with cervical spondylotic myelopathy. Eur Spine J. 2017;26(4):1205-10.

41. Wu WJ, Jiang LS, Liang Y, Dai LY. Cage subsidence does not, but cervical lordosis improvement does affect the long-term results of anterior cervical fusion with stand-alone cage for degenerative cervical disc disease: a retrospective study. Eur Spine J. 2012;21(7):1374-82.

\section{Publisher's Note}

Springer Nature remains neutral with regard to jurisdictional claims in published maps and institutional affiliations.

Ready to submit your research? Choose BMC and benefit from:
- fast, convenient online submission
- thorough peer review by experienced researchers in your field
- rapid publication on acceptance
- support for research data, including large and complex data types
- gold Open Access which fosters wider collaboration and increased citations
- maximum visibility for your research: over 100M website views per year
At BMC, research is always in progress.
Learn more biomedcentral.com/submissions

